\title{
A equidade e o financiamento em saúde no Sistema Único de Saúde - SUS
}

\author{
Flávia PORTO ${ }^{(1)}$ \\ Áquilas Nogueira MENDES ${ }^{(1)}$ \\ Samara Jamile MENDES ${ }^{(1)}$ \\ ${ }^{(1)}$ Faculdade de Saúde Pública, Universidade de São Paulo - USP, São Paulo, SP, Brasil.
}

Recebido: 28 jan 2019 Aceito: 10 fev 2019

Autor de correspondência: flaviamporto@gmail.com

Conflito de interesses: Os autores declaram não haver nenhum interesse profissional ou pessoal que possa gerar conflito de interesses em relação a este manuscrito.

\section{Resumo}

A Organização Mundial de Saúde - OMS, em seu relatório sobre o financiamento em saúde de 2015, identificou que as três principais barreiras à cobertura universal de saúde são: a disponibilidade de recursos; a confiança demasiada em pagamentos diretos do bolso e o uso ineficiente e desigual dos recursos. Uma cobertura universal de saúde efetivamente acontece quando se pode evidenciar uma utilização dos serviços coerentes às necessidades em saúde, uma assistência de saúde prestada com qualidade a população e a proteção financeira universal. Para atingir esses objetivos é preciso que exista a equidade na alocação de recursos, a eficiência, a transparência e a responsabilização. A equidade na alocação de recursos significa que indivíduos com as mesmas necessidades tenham acesso aos mesmos recursos (equidade horizontal) e indivíduos com maiores necessidades tenham acesso a mais recursos (equidade vertical). Portanto, a avaliação da equidade na alocação de recursos envolve dimensionar a correspondência entre oferta e demanda, ou seja, a alocação de recursos realizada dentro dos recursos disponíveis e as necessidades em saúde existentes. No Brasil, segundo uma revisão da literatura, a equidade é entendida como um fator essencial de justiça social na maioria dos estudos brasileiros publicados, considerando o contexto das desigualdades sociais no qual o Sistema único de Saúde - SUS está inserido. Embora poucos estudos articulem a equidade com a democracia, pode-se compreender que a busca pela equidade em saúde constitui uma forma de garantir um direito social - à saúde -, fortalecendo assim, o protagonismo do indivíduo em um sistema democrático. A revisão sugere que a discussão sobre equidade deveria ser intensificada no contexto brasileiro, considerando que o SUS lida com um orçamento limitado e uma grande demanda, o que, por vezes acaba sobrepondo os princípios de universalidade, integralidade e equidade. O desafio consiste em discutir como a distribuição de recursos escassos poderia ser mais equitativa e contínua sem que o princípio se perca ao longo do processo. Dito isso, para aprofundar as discussões sobre este tema, foi realizado o desenho deste estudo que objetiva revisar publicações que tratem do tema equidade na alocação de recursos na realidade brasileira do Sistema Único de Saúde. Objetivo: revisar publicações que tratem do tema equidade na alocação de recursos na realidade brasileira do Sistema Único de Saúde. Método: o método utilizado neste estudo será uma revisão sistemática 
integrativa sobre os artigos que discutem a equidade no financiamento em saúde no Brasil. Este método foi escolhido para sistematizar estudos com diferentes metodologias e integrar os resultados dos estudos que possivelmente abordam diversos aspectos sobre o mesmo tema. A revisão foi realizada da seguinte maneira: primeiramente, foi realizada uma busca no DeCS pelos descritores considerados chave no tema em que se pretende abordar. Desta busca, optou-se em utilizar os seguintes descritores: financiamento da assistência à saúde; eficiência na alocação; dotação de recursos para cuidados de saúde; equidade da alocação de recursos. Em seguida, foi realizada a seguinte estratégia de busca usando os descritores escolhidos no banco de dados da Biblioteca Virtual em Saúde - BVS na seguinte sequência: "Financiamento da assistência à saúde" $A N D$ "Eficiência na alocação" (41 artigos);"Financiamento da assistência à saúde" $A N D$ "Dotação de recursos para cuidados de saúde" (62 artigos); "Financiamento da assistência à saúde" $A N D$ "Equidade na alocação de recursos" (19 artigos); "Eficiência na alocação" $A N D$ "Equidade na alocação de recursos" (10 artigos); "Dotação de recursos para cuidados de saúde" $A N D$ "Equidade na alocação de recursos" (17 artigos); "Financiamento da assistência à saúde" $A N D$ "Dotação de recursos para cuidados de saúde" $A N D$ "Equidade na alocação de recursos" (4 artigos). Não foi delimitado nenhum período de datas específico. O resultado da busca usando esta estratégia descrita recuperou um total de 153 documentos. Após a realização da leitura dos títulos e resumos de cada um deles e eliminado os duplicados, prosseguiu-se avaliando os critérios de inclusão e exclusão para assim compor a revisão. Os critérios de inclusão dos documentos foram: estar disponível em língua portuguesa, inglesa ou espanhola; documentos relevantes a pergunta de investigação e ao sistema de saúde pública brasileiro; estar acessível em texto completo para leitura posterior em revistas ou biblioteca virtual das universidades em que foram publicados ou websites dos respectivos órgãos responsáveis por sua publicação. Foram excluídos da revisão as publicações disponíveis em línguas diferentes das citadas nos critérios de inclusão; as que abordavam o tema em outros países diferentes do Brasil e as que abordam outros temas não relevantes a pergunta de investigação. Dos 153 artigos, foram excluídos 18 artigos duplicados e excluídos 91, sendo 88 por tratarem do assunto em outros países e três por abordarem outros assuntos. Foram incluídos no estudo, portanto 44 artigos. Considerações finais: a maioria das publicações encontradas são teses e dissertações, enquanto o restante artigos e o restante são artigos publicados em revistas e sete são documentos oficiais de organizações nacionais e internacionais. A maioria das publicações está na língua portuguesa e apenas dois em inglês.

Descritores: Financiamento da Assistência à Saúde; Alocação de Recursos; Alocação de Recursos para Atenção à Saúde; Equidade na Alocação de Recursos. 